\title{
Self-assembled Dendritic Boronate Micelles as a Promising Delivery Strategy for Gemcitabine
}

\author{
Muna A. Al-Ni’mat, Samuel Parcero-Bouzas, Sandra P. Amaral, and Eduardo Fernandez-Megia* \\ Centro Singular de Investigación en Química Biolóxica e Materiais Moleculares (CIQUS) and Departamento de \\ Química Orgánica, Universidade de Santiago de Compostela, Jenaro de la Fuente s/n, 15782 Santiago de \\ Compostela, Spain \\ E-mail: ef.megia@usc.es
}

\begin{abstract}
Gemcitabine (GEM) is a chemotherapeutic drug widely used in the clinic to treat several types of cancer. Nevertheless, GEM presents serious shortcomings, including a short half-life and a high hydrophilicity that limit its ability to internalize cells. As a result, GEM is administered in high doses, increasing the risk of associated severe side effects. Herein, we describe a novel drug delivery system based on a PEG-dendritic copolymer functionalized with peripheral boronic acids, that self-assembles in the presence of catechol to afford nanometric micelles with the ability to encapsulate GEM. The simplicity of the method, with all equilibria (boronate esterification, copolymer self-assemble, drug encapsulation) occurring simultaneously, is compatible with a high tunability of the micelle properties (via diol structure and the boronic acid-to-diol molar ratio). Optimization of both diol and GEM loadings has afforded micelles with a size of $24 \mathrm{~nm}$, low polydispersity, and a drug loading of $8.2 \%$. These micelles displayed remarkable stability towards heating, dialysis or months at room temperature. Even, they could be lyophilized and resuspended without any variation in size. This high stability is expected to translate into improved pharmacokinetics and a more efficient delivery to tumor sites than the free drug.
\end{abstract}

Keywords: Gemcitabine, boronic acid, dendrimer, block copolymer, micelle 


\section{Introduction}

Cancer is the second leading cause of death worldwide and is expected to surpass heart disease first position in the next few years. ${ }^{1}$ According to the Global Cancer Observatory, cancer has caused an estimated 9.6 million deaths worldwide in $2018,{ }^{2}$ and this number is expected to rise to 13 million by $2030 .{ }^{3}$ Current strategies to cancer treatment include surgery, chemotherapy, radiation, and some combinations of them. Chemotherapy uses cytotoxic agents to kill or block the growth of cancer cells. ${ }^{4}$ Despite their routine use, conventional chemotherapeutic agents are plagued by drawbacks such as non-specific systemic distribution, water-solubility issues, or the development of multi-drug resistance. Among the chemotherapeutic agents used in the clinic to treat several types of cancer, the nucleoside analog gemcitabine $\left(2^{\prime}, 2^{\prime}\right.$ difluorodeoxycytidine; GEM), constitutes a promising drug. ${ }^{5}$ After initial attention for its antiviral effects, ${ }^{6}$ it was approved by the FDA as a first-line drug for the treatment of various solid tumors such as, pancreatic, non-small-cell lung, ovarian, or breast cancers. ${ }^{7,8}$ In addition, it is used in the treatment of certain lymphomas, ${ }^{10}$ and has been studied in combination therapy with other chemotherapeutics. ${ }^{11,12,13}$ Despite all the above, GEM presents serious shortcomings, including a high hydrophilicity that limits its ability to internalize cells, thus requiring from nucleoside transporter proteins to permeate the plasma membrane and exhibit pharmacological activity. ${ }^{14}$ Also, a short half-life (ca $15 \mathrm{~min}$ ) because of a rapid metabolism by cytidine deaminases. As a result, GEM needs to be administered in high doses, increasing the risk of associated severe side effects. ${ }^{15,16}$ To overcome these obstacles and increase GEM therapeutical activity, many efforts have been devoted following different approaches, including an array of drug delivery systems (DDS) like liposomes, ${ }^{17,18}$ nanoparticles, ${ }^{19}$ micelles, ${ }^{20,21}$ or prodrugs and polymer-drug conjugates. ${ }^{19,22}$

The chemotherapy efficacy of DDS depends on the optimal selection of the carrier. ${ }^{23,24,25}$ Among the various polymeric nanosystems proposed for this goal, dendrimers display unique properties. The symmetrical and globular architecture of these synthetic macromolecules, along with a well-defined structure and precise molecular weight, make dendrimers ideal candidates as templates for drug delivery applications. ${ }^{26,27}$ In parallel to the development of dendrimers, great attention has also been drawn to combine them with linear polymers to afford hybrid linear-dendritic block copolymers. ${ }^{28}$ Our research group has developed a family of such copolymers linking GATG (gallic acid-triethylene glycol) dendritic wedges ${ }^{29}$ and poly(ethylene glycol) (PEG), ${ }^{30}$ a hydrophilic linear polymer, characterized by low toxicity and immunogenicity, widely used for biomedical applications. GATG dendrimers constitute a nanoplatform for biomedical applications prepared in our laboratory. ${ }^{31,32,33,34}$ They are composed of a repeating unit incorporating a gallic acid core and hydrophilic triethylene glycol arms carrying terminal azides. When combined with PEG following a divergent strategy, the resulting PEG-GATG copolymers $^{35}$ have been exploited in a plethora of drug delivery and diagnosis applications. ${ }^{36,37,38}$ 
Boronic acids have recently emerged as an appealing functional group with a high stability and low toxicity profile. One of their most distinctive properties is the ability to form reversible covalent bonds with low molecular weight diols and polyols under aqueous conditions. ${ }^{39,40}$ The optimal $\mathrm{pH}$ for boronic ester formation is generally above the $\mathrm{pK}_{\mathrm{a}}$ of the boronic acid, whereas they are hydrolyzed at lower $\mathrm{pH}$. This renders unsubstituted boronic acids with narrow application in biological setups. The incorporation of neighboring amines (Wulff-type boronic acids) results in a lower $\mathrm{pK}_{\mathrm{a}}$ value and tetrahedral $\mathrm{sp}^{3}$ boron species at physiological $\mathrm{pH}^{41}$ This fact has popularized the use of boronic acids for glycan sensing, ${ }^{42}$ supramolecular organizations, ${ }^{43}$ sugar- and pH-responsive gels, as well as DDS. ${ }^{40}$

Herein, we describe a novel DDS based on a PEG-GATG copolymer functionalized with peripheral Wulfftype boronic acids as chemical handles for low molecular weight diols (Figure 1). After boronic ester formation in aqueous media, the increased hydrophobicity of the dendritic block (associated to both $\mathrm{OH}$ groups being transformed into OR) promotes the self-assemble of the resulting amphiphilic block copolymer into nanometric micelles as potential nanocarriers for drug encapsulation (Figure 2). The possibility of tuning the hydrophobicity of the core of these micelles via the diol structure and the boronic acid-to-diol molar ratio was anticipated as an attractive tool allowing optimization of the core environment to maximize the encapsulation of a highly hydrophilic drug such as GEM.

\section{Results and discussion}

A linear-dendritic block copolymer PEG-[G3]- $\mathrm{N}_{3}$ previously described by our group, ${ }^{35}$ which incorporates a PEG chain of $5 \mathrm{kDa}$ and a dendritic block of third generation (G3) with 27 peripheral azide groups, was selected for the functionalization with boronic acids. To this end, a one-pot, three-step protocol was implemented, comprising an initial Staudinger reduction of the terminal azides to primary amines with $\mathrm{PPh}_{3}$, followed by reductive amination with 2-formylphenylboronic in the presence of $\mathrm{NaBH}_{4}$. After $24 \mathrm{~h}$ of combined reaction time, $\mathrm{PEG}-[\mathrm{G} 3]-\mathrm{BO}_{2} \mathrm{H}_{2}$ was afforded in a very good overall yield (71\%) after a simple purification by dialysis (Figure 1). PEG-[G3]- $\mathrm{BO}_{2} \mathrm{H}_{2}$ was chemically characterized with convincing

evidence by ${ }^{1} \mathrm{H}$ and ${ }^{13} \mathrm{C}$ NMR, IR, and MALDI-TOF MS as described in the Experimental Section and Figures S1-S4. 


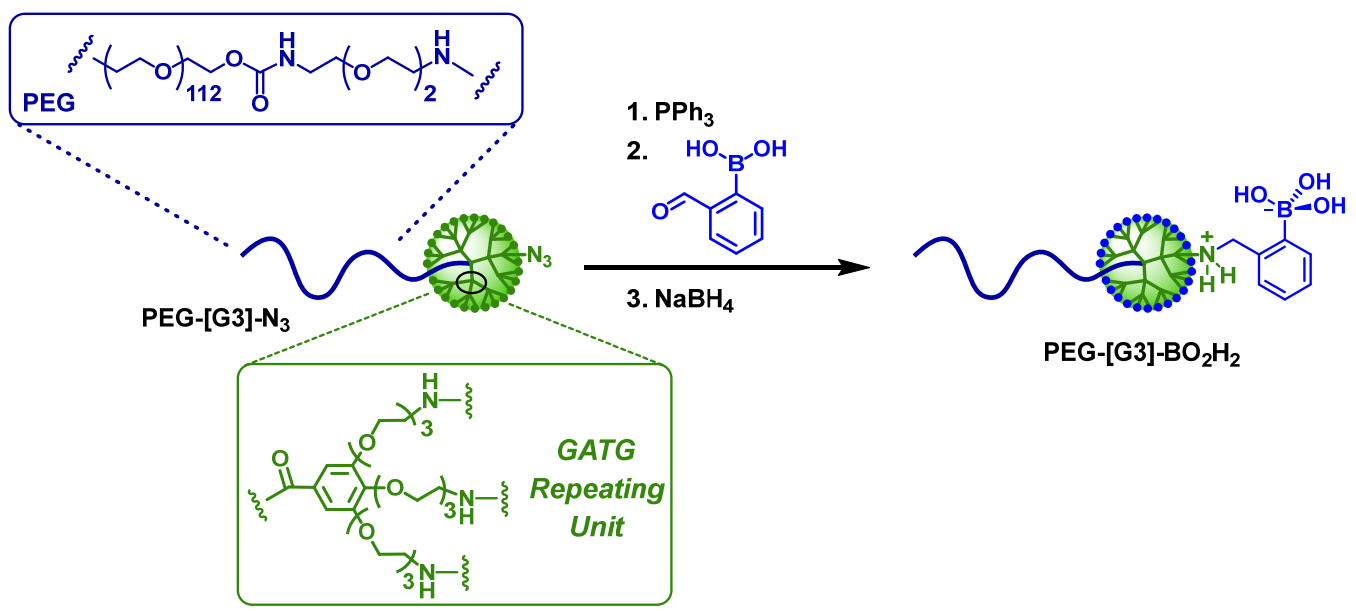

Figure 1. Synthesis of PEG-[G3]- $\mathrm{BO}_{2} \mathrm{H}_{2}$ from PEG-[G3]- $\mathrm{N}_{3}$.

An analysis of PEG-[G3]- $\mathrm{BO}_{2} \mathrm{H}_{2}$ in solution by dynamic light scattering (DLS) at different $\mathrm{pH}(4.0-11.0)$ revealed a monodisperse distribution in all cases, centered at $c a .6 \mathrm{~nm}$, assigned to the completely dispersed, non-aggregated copolymer (Figure S5). To induce the self-aggregation of PEG-[G3]- $\mathrm{BO}_{2} \mathrm{H}_{2}$ via formation of boronic esters (Figure 2A), three low molecular weight diols (ethylene glycol, 1,3-propanediol, catechol) were assessed under stoichiometric conditions at $\mathrm{pH} 8.2\left(50 \mathrm{mM}\right.$ phosphate buffer $\left.\mathrm{PB}, 25-50^{\circ} \mathrm{C}\right)$. While the first two diols did not throw any larger size distribution by DLS, catechol, a diol recognized as one of strongest boronic acid binders due to a favorable syn diol orientation, ${ }^{39}$ led after $24 \mathrm{~h}$ at $\mathrm{rt}$ to discrete micelles (denoted as $\mathrm{CAT}_{100}$ micelles, where 100 represents the mol\% of catechol relative to boronic acids) with an average size of $24 \mathrm{~nm}$ and a low polydispersity index (PDI, 0.12) (Figure 2B). As expected, control experiments with GEM, a 1,3-diol itself, did not afford micelles under any of the $\mathrm{pH}$ and temperature conditions tested.

The ability of these micelles as nanocontainers for the simultaneous micelle formation-encapsulation of GEM was assessed by tuning the relative ratios of catechol and GEM (Figure 2). Initial experiments pursued to determine the lowest catechol ratio that promotes stable PEG-[G3]- $\mathrm{BO}_{2} \mathrm{H}_{2} / \mathrm{GEM} /$ catechol micelles (denoted as $\mathrm{GEM}_{\mathrm{x}, \mathrm{y}}$ micelles, where $\mathrm{x}$ represents the $\mathrm{mol} \%$ of GEM and $\mathrm{y}$ the $\mathrm{mol} \%$ of catechol relative to boronic acids). Lower catechol ratios were expected to afford cores more compatible with the hydrophilicity of GEM. With this aim, the formation of micelles was assessed using a fixed $85 \%$ GEM and different proportions of catechol $(4,8,12$, and $15 \%)$ in $50 \mathrm{mM} \mathrm{PB} \mathrm{pH} 8.2$, at $37-50^{\circ} \mathrm{C}$. While 4 and $8 \%$ of catechol led to polydispersed distributions by DLS, mainly centered below $10 \mathrm{~nm}$ and assigned to the non-aggregated copolymer (Figure S6), increasing the catechol content afforded more uniform micelles at $50{ }^{\circ} \mathrm{C}$. GEM 85,15 micelles with $15 \%$ catechol showed the lowest PDI and highest stability, even when dialyzed towards 50

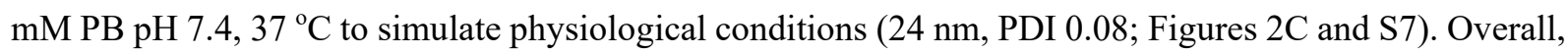


$15 \%$ represents the lowest catechol ratio ensuring the formation of stable micelles for the in-situ encapsulation of GEM. As expected, control $\mathrm{CAT}_{15}$ micelles (no GEM) show similar size and PDI to GEM $_{85,15}$ by DLS (Figure S8).

The encapsulation efficiency (EE) and drug loading (DL) of $\mathrm{GEM}_{85,15}$ were determined by quantifying the amount of non-encapsulated GEM after $4 \mathrm{~h}$ dialysis $\left(50 \mathrm{mM} \mathrm{PB} \mathrm{pH} 7.4,37^{\circ} \mathrm{C}\right)$ by reverse phase-high performance liquid chromatography (RP-HPLC) (Figure S10). No further release of GEM was observed at longer dialysis times (Figure S9). This way, an EE of 9.8\% and DL of 3.5\% were revealed for GEM $_{85,15}$.
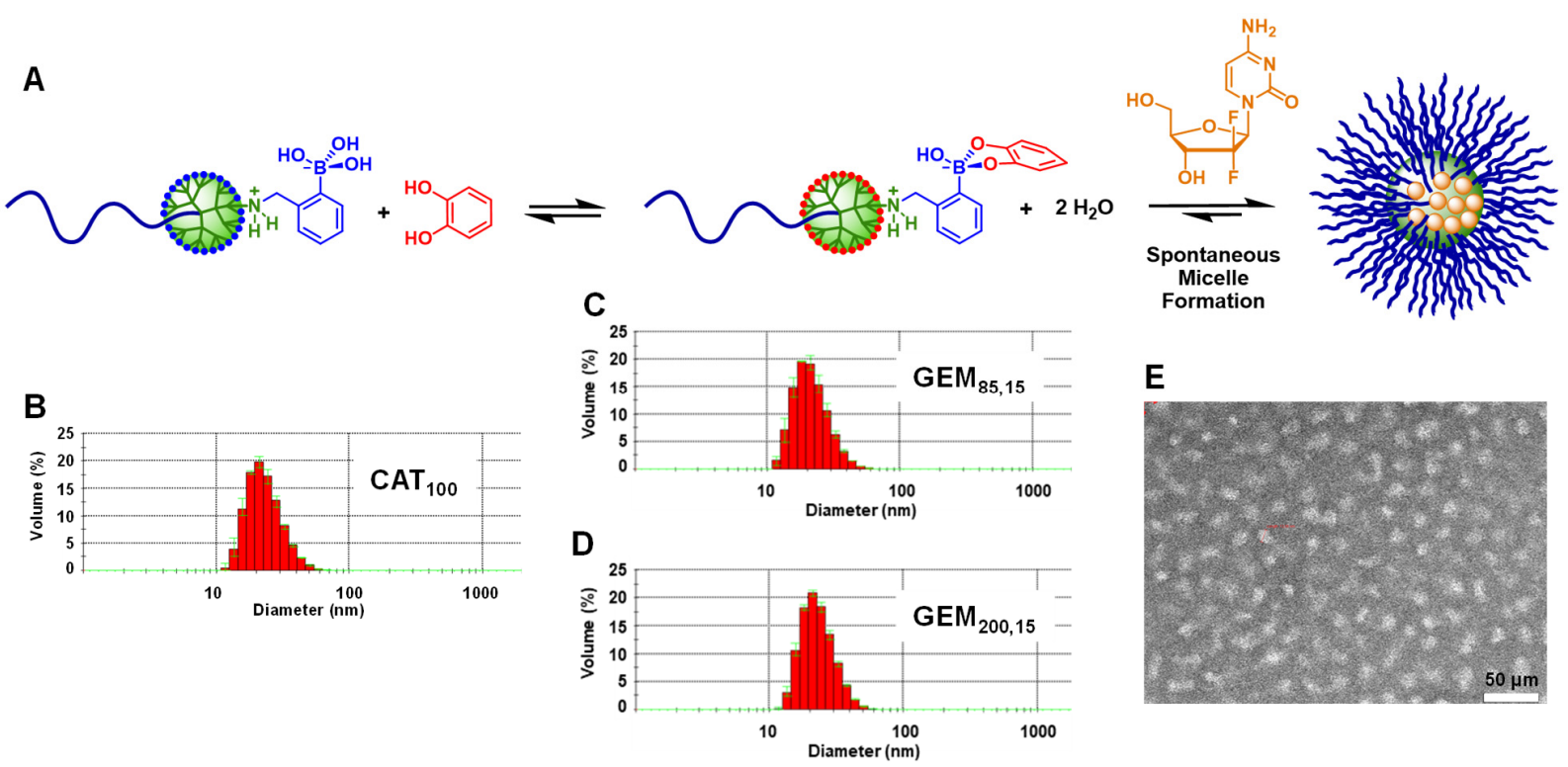

E

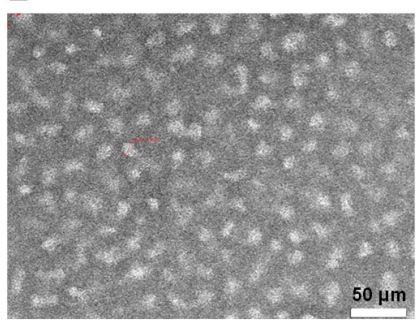

Figure 2. PEG-dendritic boronic ester formation, followed by in-situ self-assemble and encapsulation of GEM (A). DLS histograms (50 mM PB pH 7.4, $37^{\circ} \mathrm{C}$ ) of CAT 100 (B), $\mathrm{GEM}_{85,15}$ (C) and $\mathrm{GEM}_{200,15}$ (D) micelles. TEM image of $\mathrm{GEM}_{200,15}$ micelles (E).

Having determined the minimum content of catechol for a reproducible micelle formation and encapsulation of GEM, it was our intention to rise the DL of the micelles. Considering the hydrophilic nature of the drug, it was anticipated that increasing the GEM feeding ratio, while keeping all other conditions unchanged, could afford higher GEM loadings. Gratifyingly, GEM $_{200,15}$ micelles with $200 \%$ GEM revealed undistinguishable to GEM $_{85,15}$ in size, PDI and EE (24 nm, PDI 0.08, EE 10.3\%; Figures 2D and S7), but showed a 2.4 -fold increase in DL, up to $8.2 \%$ (Figure S10). This value, proportional to the increase in GEM feeding ratio, is remarkable considering the hydrophilic nature of GEM and simplicity of the procedure. Interestingly, when the micelle formation time was increased from $15 \mathrm{~h}$ to 24 or $48 \mathrm{~h}$, no effect on the EE and DL values was observed. $\mathrm{GEM}_{200,15}$ micelles were further characterized by transmission electron microscopy (TEM), displaying uniform shape with size in the range of 20-25 nm that 
matches that obtained by DLS (Figure 2E). In addition, z-potential measurements revealed a value close to zero (+2.91 mV, Figure S11), consistent with a high colloidal stability.

Although polymeric micelles have shown promising pharmaceutical potential, several limitations hamper their clinical translation. The most serious drawbacks include poor micelle stability in biological fluids and insufficient circulation time in the blood stream. This results in rapid blood clearance, premature drug release, and consequently, poor tumor targeting. Hence, a study of the stability of $\mathrm{GEM}_{200,15}$ micelles was performed by DLS under challenging conditions, such as $24 \mathrm{~h}$ of heating or extensive dialysis towards simulated physiological conditions (50 mM PB pH 7.4, $37^{\circ} \mathrm{C} ; 150 \mathrm{mM}$ ionic strength). The stability of the micelles was also studied for 6 months at $4{ }^{\circ} \mathrm{C}$ or rt at pH 7.4. As clearly shown in Figure 3, the integrity of the micelles was not compromised under any of the conditions tested. Neither the DLS histograms nor correlations functions were even minimally affected. Remarkably, $\mathrm{GEM}_{200,15}$ micelles could be even lyophilized and resuspended without any variation in size and PDI, which represents a relevant property for easy storage and handling (Figure 3). 
A

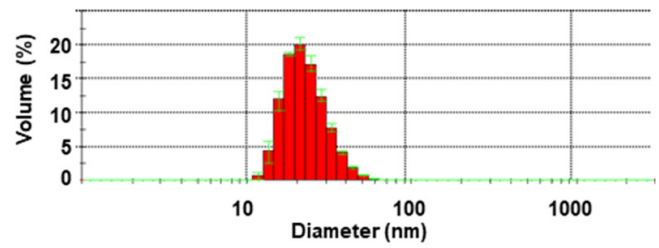

B

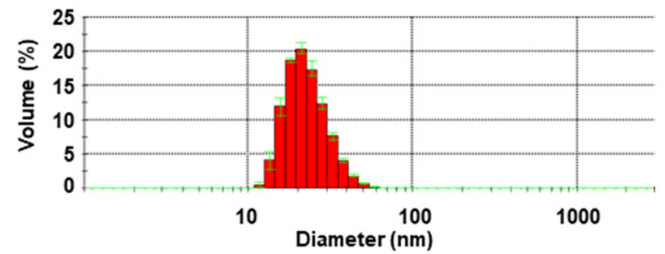

C
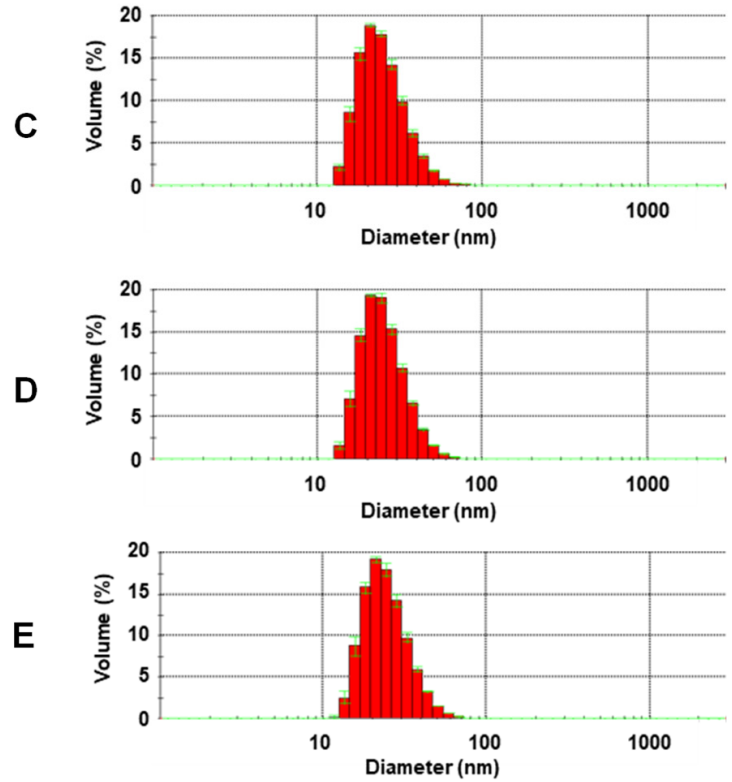
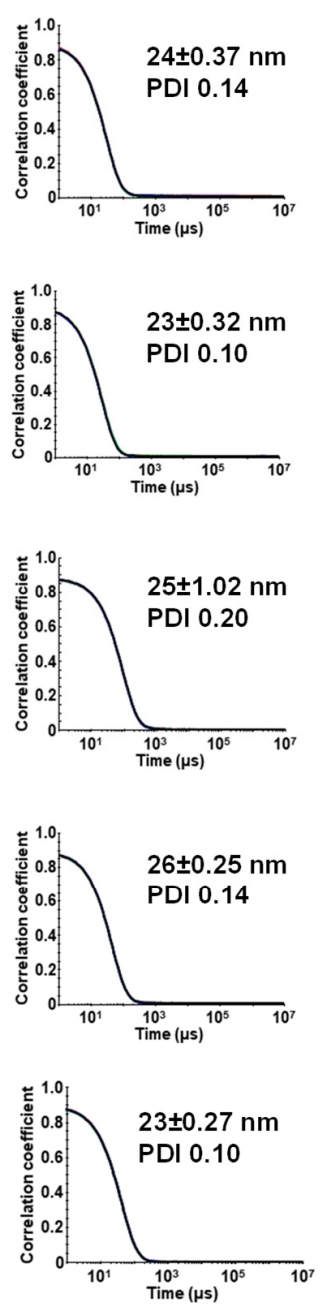

Figure 3. DLS histograms (left) and correlation functions (right) of $\mathrm{GEM}_{200,15}$ micelles (50 $\mathrm{mM} \mathrm{PB} \mathrm{pH}$

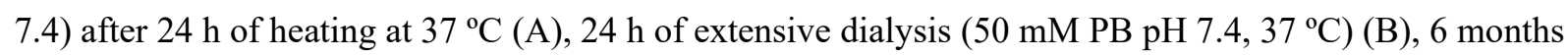
at $4{ }^{\circ} \mathrm{C}$ or $\mathrm{rt}(\mathrm{C}$ and $\mathrm{D})$, and after lyophilization and resuspension in Milli-Q water (E).

Finally, the cytotoxicity of GEM $_{200,15}$ was investigated in human adenocarcinoma alveolar basal epithelial (A549) cells by MTT, using free GEM, PEG-[G3]- $\mathrm{BO}_{2} \mathrm{H}_{2}$, and $\mathrm{CAT}_{15}$ micelles (identical to $\mathrm{GEM}_{200,15}$ but lacking any loaded GEM) as controls at the same concentrations as in $\mathrm{GEM}_{200,15}$. As shown in Figure 4, the block copolymer and control $\mathrm{CAT}_{15}$ showed negligible cytotoxicity for A549 cells after incubation for 48 h. Conversely, on increasing the drug concentration, free GEM and $\mathrm{GEM}_{200,15}$ micelles displayed increased toxicity ( $\mathrm{IC}_{50} 12$ and $289 \mathrm{nM}$, respectively) (Figure 4). Beyond the obtained $\mathrm{IC}_{50}$ values, the high stability of $\mathrm{GEM}_{200,15}$ is expected to translate into improved pharmacokinetics and more efficient delivery to tumor sites. Indeed, several reports have described anticancer DDS that, being less effective in vitro than the free drug, afforded substantially superior antitumor efficacy in animal models. ${ }^{44,45}$ In this regard, in vivo 
experiments will be the focus of future work to fully assess the therapeutic activity of our findings. Application of this technology to alternative diols and drugs is underway.

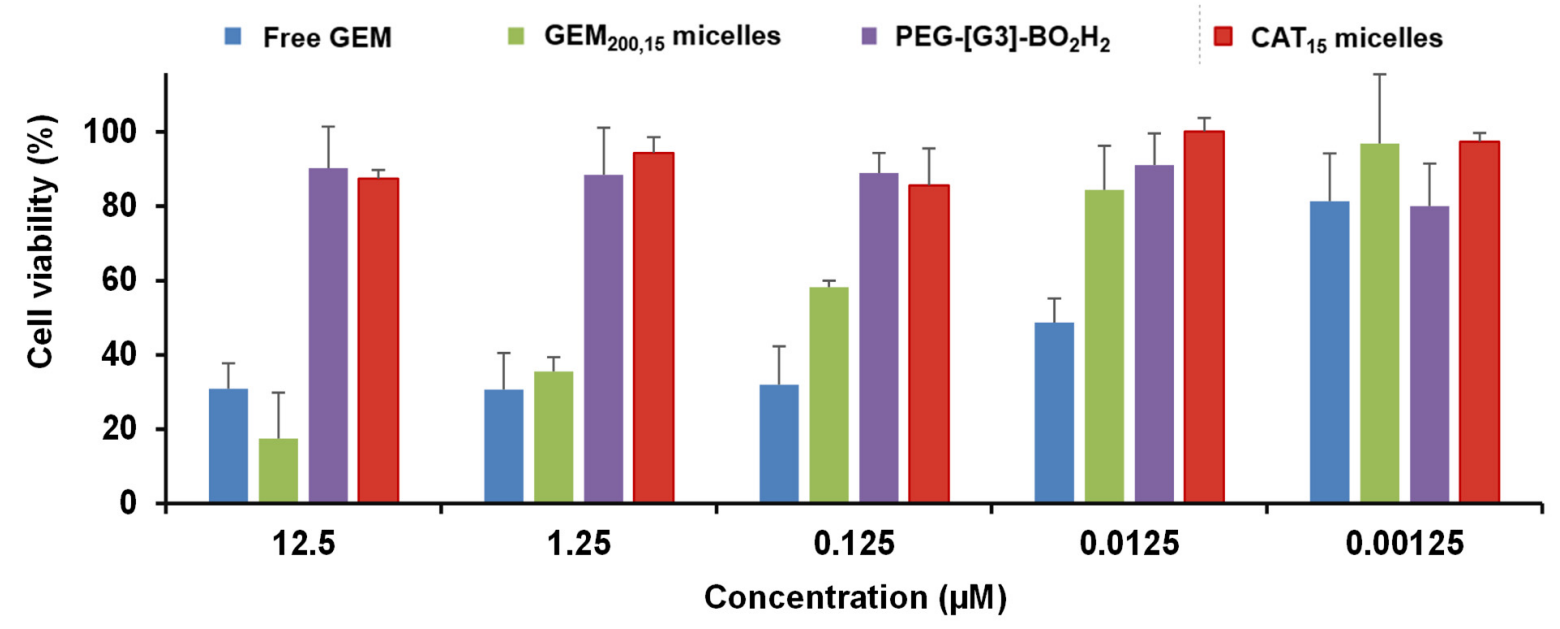

Figure 4. Cell viability (MTT, 48 h) of A549 cells in the presence of GEM$_{200,15}$ micelles and controls (free GEM, PEG-[G3]- $\mathrm{BO}_{2} \mathrm{H}_{2}$, and $\mathrm{CAT}_{15}$ micelles) at the same concentrations as in the micelle.

\section{Conclusions}

Herein, we describe a novel drug delivery system based on a PEG-dendritic copolymer functionalized with peripheral boronic acids, that self-assembles in the presence of diols to afford nanometric micelles with the ability to encapsulate drugs. The simplicity of the method, with all equilibria (boronate esterification, copolymer self-assemble, drug encapsulation) occurring simultaneously, is compatible with a high tunability of the micelle properties (via diol structure and boronic acid-to-diol molar ratio). Using catechol as diol and GEM as a model hydrophilic drug, optimized micelles were obtained with a size of $24 \mathrm{~nm}$, low polydispersity, and drug loading of $8.2 \%$. These micelles displayed remarkable stability towards heating, months at room temperature, and lyophilization-resuspension, which is expected to translate into improved pharmacokinetics and more efficient delivery to tumor sites than the free drug. Application of this technology to alternative diols and drugs is underway. 


\section{Experimental Section}

\section{General methods}

Materials. $\mathrm{PPh}_{3}$ was purchased from Sigma-Aldrich and recrystallized from ethanol. Gemcitabine (GEM) was purchased from Fluorochem and 2-formylphenylboronic acid from Sigma-Aldrich. All other chemicals were obtained from Sigma-Aldrich or Acros and used without further purification. All solvents were HPLC grade from Scharlab, Sigma-Aldrich, or Acros and used without further purification. PEG-[G3]-N 3 was prepared from a commercial MeO-PEG-OH of $5000 \mathrm{Da}$ as earlier decribed. ${ }^{35}$ The GATG repeating unit was prepared following reported procedures by our group. ${ }^{46} \mathrm{H}_{2} \mathrm{O}$ of Milli-Q grade was obtained using a Millipore water purification system.

NMR spectroscopy. NMR spectra were recorded on a Bruker DRX $500 \mathrm{MHz}$ spectrometer. Chemical shifts are reported in ppm ( $\delta$ units) downfield from the HOD solvent peak $\left(\mathrm{D}_{2} \mathrm{O}\right)$. All spectra were processed using Mestre Nova 9.0.0 software (Mestrelab Research).

Determination of $\mathbf{p H}$ values. $\mathrm{pH}$ values were measured with a portable $\mathrm{pH}-\mathrm{meter}$ (Crison $\mathrm{PH} 25$ ) connected to a glass electrode (Crison 52 09).

Ultrafiltration and dialysis. Purifications by ultrafiltration were performed on Millipore Amicon stirred cells using Amicon YM1 regenerated cellulose membranes (MWCO $1 \mathrm{kDa}$ ) under 5 psi $\mathrm{N}_{2}$ pressure. Dialysis was performed with $18 \mathrm{~mm}$ Spectra/Por $6 \mathrm{MWCO} 1 \mathrm{kDa}$ membrane tubing from SpectrumLabs.

Infrared spectroscopy. FT-IR spectra were recorded on a Perkin-Elmer Spectrum Two equipped with a UATR accessory.

Dynamic light scattering (DLS). DLS measurements were performed on a Malvern Nano ZS (Malvern Instruments, U.K.) operating at $633 \mathrm{~nm}$ with a $173^{\circ}$ scattering angle at $4,25,37$, or $50^{\circ} \mathrm{C}$. Hydrodynamic diameters of micelles $(1 \mathrm{mg} / \mathrm{mL})$ were measured in $\mathrm{H}_{2} \mathrm{O}$ or buffer solutions. DLS mean diameters were obtained from the volume particle size distribution provided by Malvern Zetasizer Software. DLS histograms were obtained from the volume and intensity particle size distributions.

Transmission electron microscopy (TEM). TEM measurements were performed on a JEOL JEM1011 operated at $80 \mathrm{kV}$. Samples were ultrafiltered against Milli-Q water (Amicon YM1, MWCO $1 \mathrm{kDa}$ ) to remove salts. A drop of micellar solution fixed with $2.5 \%$ glutaraldehyde was settled on carbon Type-B coated copper grids and allowed to dry at $\mathrm{rt}$ for $1 \mathrm{~h}$. Negative staining was performed by using a droplet of $2 \%$ uranyl acetate following standard procedures.

Z-Potential. The Z-potential of the micelles was obtained by laser doppler anemometry (LDA), measuring the mean electrophoretic mobility (Malvern Zetasizer Nano ZS, Malvern Instruments). Measurements were 
performed in $50 \mathrm{mM}$ PB pH 7.4 (Hückel approximation). GEM 200,15 micelles revealed a Z-potential value close to zero: $+2.91 \mathrm{mV}$.

\section{Synthesis of PEG-[G3]-BO ${ }_{2} \mathrm{H}_{2}$}

$\mathrm{PPh}_{3}(60 \mathrm{mg}, 0.23 \mathrm{mmol})$ was added to a solution of PEG-[G3]- $\mathrm{N}_{3}(100 \mathrm{mg}, 7.70 \mu \mathrm{mol})$ in $5 \% \mathrm{MeOH} / \mathrm{H}_{2} \mathrm{O}$ $(2.1 \mathrm{~mL})$. After $8 \mathrm{~h}$ of stirring at $\mathrm{rt}, 2$-formylphenylboronic acid $(46.7 \mathrm{mg}, 0.31 \mathrm{mmol})$ was added and stirring continued for $12 \mathrm{~h}$ before the addition of $\mathrm{NaBH}_{4}(11.8 \mathrm{mg}, 0.31 \mathrm{mmol})$. After $4 \mathrm{~h}$ of stirring, the solvent was evaporated. The crude product was dissolved in $\mathrm{H}_{2} \mathrm{O}$ and dialysed $\left(40 \% \mathrm{MeOH} / \mathrm{H}_{2} \mathrm{O}, 8 \times 1 \mathrm{~L}\right.$ and Milli-Q $\mathrm{H}_{2} \mathrm{O}, 8 \times 1 \mathrm{~L}$, MWCO $1 \mathrm{kDa}$ ). After lyophilization, PEG-[G3]- $\mathrm{BO}_{2} \mathrm{H}_{2}$ was obtained as a white solid (89.3 mg, 73\%). ${ }^{1} \mathrm{H}$ NMR (500 MHz, $\left.\mathrm{D}_{2} \mathrm{O}\right)$ 8: 7.43-7.34 (m, 27H), 7.22-6.91 (m, 107H), 4.20-3.45 (m, 1028H), 3.43 (s, 3H), 3.25 (br s, 2H), 3.01 (br s, 54H). ${ }^{13} \mathrm{C}$ NMR $\left(125 \mathrm{MHz}, \mathrm{D}_{2} \mathrm{O}\right) \delta$ :

168.4, 151.6, 145.5, 141.0, 139.3, 129.0, 127.4, 127.0, 122.4, 106.0, 71.9, 70.9, 69.9, 69.5, 69.0, 68.1, 66.7, 66.6, 58.0, 52.4, 45.6, 39.6, 39.3. IR (ATR) $v_{\max }: 3437,2874,1714,1352,1113 \mathrm{~cm}^{-1}$. MALDI-TOF MS (DHB, linear mode): $\mathrm{m} / \mathrm{z}$ Calcd: $\mathrm{M}_{\mathrm{p}} 15913$ ([M+Na] $\left.]^{+}\right), \mathrm{M}_{\mathrm{n}}$ 15854; Found: $\mathrm{M}_{\mathrm{p}}$ 15978, $\mathrm{M}_{\mathrm{n}} 16026, \mathrm{M}_{\mathrm{w}} 16096$.

\section{Preparation of GEM , $15_{\text {micelles }}$}

PEG-[G3]- $\mathrm{BO}_{2} \mathrm{H}_{2}(5 \mathrm{mg} / \mathrm{mL})$, catechol $(1 \mathrm{mg} / \mathrm{ml})$ and GEM $(2 \mathrm{mg} / \mathrm{mL})$ were separately dissolved in 50 $\mathrm{mM}$ phosphate buffer (PB) $\mathrm{pH}$ 8.2. The solutions were filtered through $0.45 \mu \mathrm{m}$ PTFE aqueous filters. Micelles were prepared by adding the PEG-[G3]- $\mathrm{BO}_{2} \mathrm{H}_{2}$ solution $(200 \mu \mathrm{L})$ to the GEM solution $(185 \mu \mathrm{L}$ for $\mathrm{GEM}_{85,15}$ or $435 \mu \mathrm{L}$ for $\left.\mathrm{GEM}_{200,15}\right)$. Finally, the catechol solution $(27 \mu \mathrm{L})$ was added as the last component to the mixture. The volume was adjusted to $1 \mathrm{~mL}$ with the same buffer. The flask was covered with aluminum foil and stirred at $50{ }^{\circ} \mathrm{C}$ for $15 \mathrm{~h}$. Micelle formation was confirmed by DLS at the same temperature.

\section{Encapsulation efficiency (EE), drug loading (DL) and in vitro Release}

- Encapsulation efficiency (EE) describes the fraction of drug incorporated into a micelle compared to the total amount of drug used in its preparation $(\mathrm{EE}=$ weight of drug in micelle $\times 100 /$ weight of feeding drug). - Drug loading (DL) refers to the mass fraction of a micelle that is composed of the drug (DL = weight of drug in micelle $\times 100 /$ weight of drug-loaded micelle).

The EE and DL of GEM in GEM $_{x, y}$ micelles were determined by reverse phase-high performance liquid chromatography (RP-HPLC) as follows. A solution $(1 \mathrm{~mL})$ of readily prepared $\mathrm{GEM}_{\mathrm{x}, \mathrm{y}}$ micelles $(50 \mathrm{mM}$

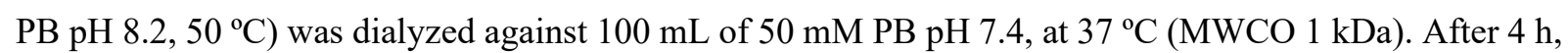
aliquots of the buffer solution $(3 \times 1 \mathrm{~mL})$ were taken and filtered through $0.45 \mu \mathrm{m}$ Nylon aqueous filters. 
These samples were analyzed by RP-HPLC with an Agilent 1100 series separation module connected to a SunFire ${ }^{\mathrm{TM}} \mathrm{C} 18$ column ( $5 \mu \mathrm{L}, 4.6 \times 150 \mathrm{~mm}$ ) and an Agilent 1100 series (UV) detector operating at 254 $\mathrm{nm}$. An isocratic elution with $93: 7 \mathrm{v} / \mathrm{v}$ of $10 \mathrm{mM} \mathrm{PB} \mathrm{pH} \mathrm{7.4/methanol} \mathrm{at} 0.5 \mathrm{~mL} / \mathrm{min}$ was used. The injection volume was $30 \mu \mathrm{L}$. Under these conditions, the retention time of GEM was found to be $12.0 \pm 0.5 \mathrm{~min}$. Spectra Manager ${ }^{\mathrm{TM}}$ II software was used to determine the GEM concentration in injected samples by comparing the area under the peak with a standard calibration curve made from the absorbance peak of fresh solutions of GEM of known concentrations prepared under identical conditions. The values are averages of three replicates. For determining the release profile of the micelles, the same protocol was applied while taking $1 \mathrm{~mL}$ aliquots during $10 \mathrm{~h}$.

\section{Cell Studies}

Cell Cultures. Human adenocarcinoma alveolar basal epithelial (A549) cells, obtained from the European Collection of Authenticated Cell Cultures (ECACC), were cultured at $37{ }^{\circ} \mathrm{C}$ in $5 \% \mathrm{CO}_{2}$ atmosphere in Dulbecco's modified Eagle's medium (DMEM) with high glucose, containing 10\% fetal bovine serum (FBS) and supplemented with $50 \mathrm{U} / \mathrm{mL}$ penicillin and $50 \mathrm{U} / \mathrm{mL}$ streptomycin. All cell experiments were performed with this modified DMEM containing 10\% FBS and simply referred in the text as "medium".

Cytotoxicity Assays. A549 cells were seeded in a 96-well microplate (4000 cells/well) in $100 \mu \mathrm{L}$ of DMEM supplemented with $10 \% \mathrm{FBS}$ and maintained at $37{ }^{\circ} \mathrm{C}$ in a $5 \% \mathrm{CO}_{2}$ atmosphere for $24 \mathrm{~h}$. Then, growth medium was replaced by fresh medium containing different concentrations of micelles and incubated for $48 \mathrm{~h}$. Afterwards, $10 \mu \mathrm{L}$ of a MTT [3-(4,5-dimethylthiazol-2-yl)-2,5-diphenyltetrazolium bromide] solution $(5 \mathrm{mg} / \mathrm{mL}$ in PBS) were added to each plate and incubated for $4 \mathrm{~h}$, before $100 \mu \mathrm{L}$ of solubilizing solution $(10 \% \mathrm{SDS}$ in $0.01 \mathrm{M} \mathrm{HCl})$ were added and the resulting mixtures incubated overnight. Absorbance was read at $570 \pm 10 \mathrm{~nm}$ in a microplate reader (Tecan Infinite F200 PRO) and the relative cell viability was calculated according to: $\left(\mathrm{A}_{\text {sample }}-\mathrm{A}_{\text {blank }} / \mathrm{A}_{\text {control }}-\mathrm{A}_{\text {blank }}\right) \times 100$, where $\mathrm{A}_{\text {sample }}$ corresponds to the absorbance of well with cells treated with a determined sample, $A_{\text {blank }}$ to the absorbance of well without cells, and $A_{\text {control }}$ to the absorbance of well with untreated cells.

\section{Acknowledgements}

This work was financially supported by the Spanish Ministry of Science and Innovation (RTI2018-102212B-I00), the Xunta de Galicia (ED431C 2018/30, and Centro singular de investigación de Galicia accreditation 2019-2022, ED431G2019/03), and the European Union (European Regional Development Fund-ERDF). 


\section{References}

${ }^{1}$ Siegel, R. L.; Miller, K. D.; Jemal, A. CA Cancer J. Clin. 2015, 65, 5.

${ }^{2}$ Ferlay, J.; Colombet, M.; Soerjomataram, I.; Mathers, C.; Parkin, D.M.; Piñeros, M.; Znaor, A.; Bray, F. Int. J. Cancer. 2019, 144, 1941.

${ }^{3}$ Ferlay J, Ervik M, Lam F, Colombet M, Mery L, Piñeros M, Znaor A, Soerjomataram I, Bray F (2018). Global Cancer Observatory: Cancer Tomorrow. Lyon, France: International Agency for Research on Cancer. Retrieved

from https://gco.iarc.fr/tomorrow/graphicisotype?type=0\&type sex=0\&mode=population\&sex=0\&populations $=900 \&$ cancers $=39 \&$ age group $=$ value \&apc_male $=0 \&$ apc female $=0 \&$ single unit $=500000 \&$ print $=0$.

Accessed (2020, October).

${ }^{4}$ Zhang, W.; Zhang, Z.; Zhang, Y. Nanoscale Res. Lett. 2011, 6, 555.

${ }^{5}$ Jordheim, L. P.; Durantel, D.; Zoulim, F.; Dumontet, C. Nat. Rev. Drug Discov. 2013, $12,447$.

${ }^{6}$ Bianchi, V.; Borella, S.; Calderazzo, F.; Ferraro, P.; Bianchi, L. C.; Reichard, P. P. Natl. Acad. Sci. 1994, 91, 8403.

${ }^{7}$ Fuchs, C. S.; Azevedo, S.; Okusaka, T.; Van Laethem, J.-L.; Lipton, L.; Riess, H.; Szczylik, C.; Moore, M.; Peeters, M.; Bodoky, G. Ann. Oncol. 2015, 26, 921.

${ }^{8}$ Khare, V.; Kour, S.; Alam, N.; Dubey, R. D.; Saneja, A.; Koul, M.; Gupta, A. P.; Singh, D.; Singh, S. K.; Saxena, A. K. Int. J. Pharm. 2014, 470, 51.

${ }^{9}$ Celia, C.; Cosco, D.; Paolino, D.; Fresta, M. Expert Opin. Drug Del. 2011, 8, 1609.

${ }^{10}$ Wong, A.; Soo, R. A.; Yong, W.-P.; Innocenti, F. Drug Metab. Rev. 2009, 41, 77.

${ }^{11}$ Aryal, S.; Hu, C.-M. J.; Zhang, L. Small 2010, 6, 1442.

${ }^{12}$ Liu, D.; Chen, Y.; Feng, X.; Deng, M.; Xie, G.; Wang, J.; Zhang, L.; Liu, Q.; Yuan, P. Colloids Surf. B 2014, 113, 158 .

${ }^{13}$ Zhang, J.; Miao, L.; Guo, S.; Zhang, Y.; Zhang, L.; Satterlee, A.; Kim, W. Y.; Huang, L. J. Control. Release 2014, 182, 90 .

${ }^{14}$ Mackey, J. R.; Mani, R. S.; Selner, M.; Mowles, D.; Young, J. D.; Belt, J. A.; Crawford, C. R.; Cass, C. E. Cancer Res. 1998, 58, 4349.

${ }^{15}$ Moog, R.; Burger, A.; Brandl, M.; Schüler, J.; Schubert, R.; Unger, C.; Fiebig, H.; Massing, U. Cancer Chemoth. Pharm. 2002, 49, 356.

${ }^{16}$ Reid, J. M.; Qu, W.; Safgren, S. L.; Ames, M. M.; Krailo, M. D.; Seibel, N. L.; Kuttesch, J.; Holcenberg, J. J. Clin. Oncol. 2004, 22, 2445.

${ }^{17}$ Immordino, M. L.; Brusa, P.; Rocco, F.; Arpicco, S.; Ceruti, M.; Cattel, L. J. Control. Release 2004, 100, 331.

${ }^{18}$ Bornmann, C.; Graeser, R.; Esser, N.; Ziroli, V.; Jantscheff, P.; Keck, T.; Unger, C.; Hopt, U.; Adam, U.; Schaechtele, C. Cancer Chemoth. Pharm. 2008, 61, 395.

${ }^{19}$ Arias, J. L.; Reddy, L. H.; Couvreur, P. J. Drug Target. 2009, 17, 586.

${ }^{20}$ Daman, Z.; Ostad, S.; Amini, M.; Gilani, K. Int. J. Pharm. 2014, 468, 142.

${ }^{21}$ Zhu, S.; Wonganan, P.; Lansakara-P, D. S.; O'Mary, H. L.; Li, Y.; Cui, Z. Biomaterials 2013, $34,2327$.

${ }^{22}$ Vandana, M.; Sahoo, S. K. Biomaterials 2010, 31, 9340.

${ }^{23}$ Hare, J. I.; Lammers, T.; Ashford, M. B.; Puri, S.; Storm, G.; Barry, S. T. Adv. Drug Delivery Rev. 2017, 108, 25.

${ }^{24}$ Zhang, Y.; Cao, Y.; Luo, S.; Mukerabigwi, J. F.; Liu, M. In Nanobiomaterials in Cancer Therapy; William Andrew Publishing: 2016, p 253.

${ }^{25}$ Tibbitt, M. W.; Dahlman, J. E.; Langer, R. J. Am. Chem. Soc. 2016, 138, 704.

${ }^{26}$ Kannan, R. M.; Nance, E.; Kannan, S.; Tomalia, D. A. J. Intern. Med. 2014, 276, 579.

${ }^{27}$ Tekade, R. K.; Kumar, P. V.; Jain, N. K. Chem. Rev. 2009, 109, 49.

${ }^{28}$ Sousa-Herves, A.; Riguera, R.; Fernandez-Megia, E. New J. Chem. 2012, 36, 205. 
${ }^{29}$ Sousa-Herves, A.; Novoa-Carballal, R.; Riguera, R.; Fernandez-Megia, E. AAPS J. 2014, 16, 948.

${ }^{30}$ Knop, K.; Hoogenboom, R.; Fischer, D.; Schubert, U. S. Angew. Chem., Int. Ed. 2010, 49, 6288.

${ }^{31}$ Vukojicic, P.; Béhar, G.; Tawara, M. H.; Fernandez-Villamarin, M.; Pecorari, F.; Fernandez-Megia, E.; Mouratou, B. ACS Appl. Mater. Interfaces 2019, 11, 21391.

${ }^{32}$ Neira, J. L.; Correa, J.; Rizzuti, B.; Santofimia-Castaño, P.; Abian, O.; Velázquez-Campoy, A.; Fernandez-Megia, E.; Iovanna, J. L. Biomacromolecules 2019, 20, 2567.

${ }^{33}$ Amaral, S. P.; Tawara, M. H.; Fernandez-Villamarin, M.; Borrajo, E.; Martínez-Costas, J.; Vidal, A.; Riguera, R.; Fernandez-Megia, E. Angew. Chem., Int. Ed. 2018, 57, 5273.

${ }^{34}$ Munoz, E. M.; Correa, J.; Riguera, R.; Fernandez-Megia, E. J. Am. Chem. Soc. 2013, 135, 5966.

${ }^{35}$ Fernandez-Villamarin, M.; Sousa-Herves, A.; Correa, J.; Munoz, E. M.; Taboada, P.; Riguera, R.; Fernandez-Megia, E. ChemNanoMat 2016, 2, 437.

${ }^{36}$ Lopez-Blanco, R.; Fernandez-Villamarin, M.; Jatunov, S.; Novoa-Carballal, R.; Fernandez-Megia, E. Polym. Chem. 2019, 10, 4709.

${ }^{37}$ Sousa-Herves, A.; Sánchez Espinel, C.; Fahmi, A.; González-Fernández, Á.; Fernandez-Megia, E. Nanoscale 2015, 7, 3933.

${ }^{38}$ Fernandez-Trillo, F.; Pacheco-Torres, J.; Correa, J.; Ballesteros, P.; Lopez-Larrubia, P.; Cerdan, S.; Riguera, R.; Fernandez-Megia, E. Biomacromolecules 2011, 12, 2902.

${ }^{39}$ Hall, D. G. Structure, Properties, and Preparation of Boronic Acid Derivatives. Overview of Their Reactions and Applications; WILEY-VCH Verlag: Weinheim, 2005.

${ }^{40}$ Brooks, W. L. A.; Sumerlin, B. S. Chem. Rev. 2016, 116, 1375.

${ }^{41}$ Wulff, G. Pure Appl. Chem. 1982, 54, 2093.

${ }^{42}$ Sun, X.; James, T. D. Chem. Rev. 2015, 115, 8001.

${ }^{43}$ Kubo, Y.; Nishiyabu, R.; James, T. D. Chem. Commun. 2015, 51, 2005.

${ }^{44}$ Lee, C. C.; Gillies, E. R.; Fox, M. E.; Guillaudeu, S. J.; Fréchet, J. M. J.; Dy, E. E.; Szoka, F. C. Proc. Natl. Acad. Sci. U.S.A. 2006, 103, 16649.

${ }^{45}$ MacKay, J. A.; Chen, M.; McDaniel, J. R.; Liu, W.; Simnick, A. J.; Chilkoti, A. Nat. Mater. 2009, 8, 993.

${ }^{46}$ Amaral, S. P.; Fernandez-Villamarin, M.; Correa, J.; Riguera, R.; Fernandez-Megia, E. Org. Lett. 2011, 13,4522 . 
Supporting Information for

\title{
Self-assembled Dendritic Boronate Micelles as a Promising Delivery Strategy for Gemcitabine
}

\author{
Muna A. Al-Ni'mat, Samuel Parcero-Bouzas, Sandra P. Amaral, and Eduardo Fernandez-Megia* \\ Centro Singular de Investigación en Química Biolóxica e Materiais Moleculares (CIQUS) and Departamento de \\ Química Orgánica, Universidade de Santiago de Compostela, Jenaro de la Fuente s/n, 15782 Santiago de
} Compostela, Spain 


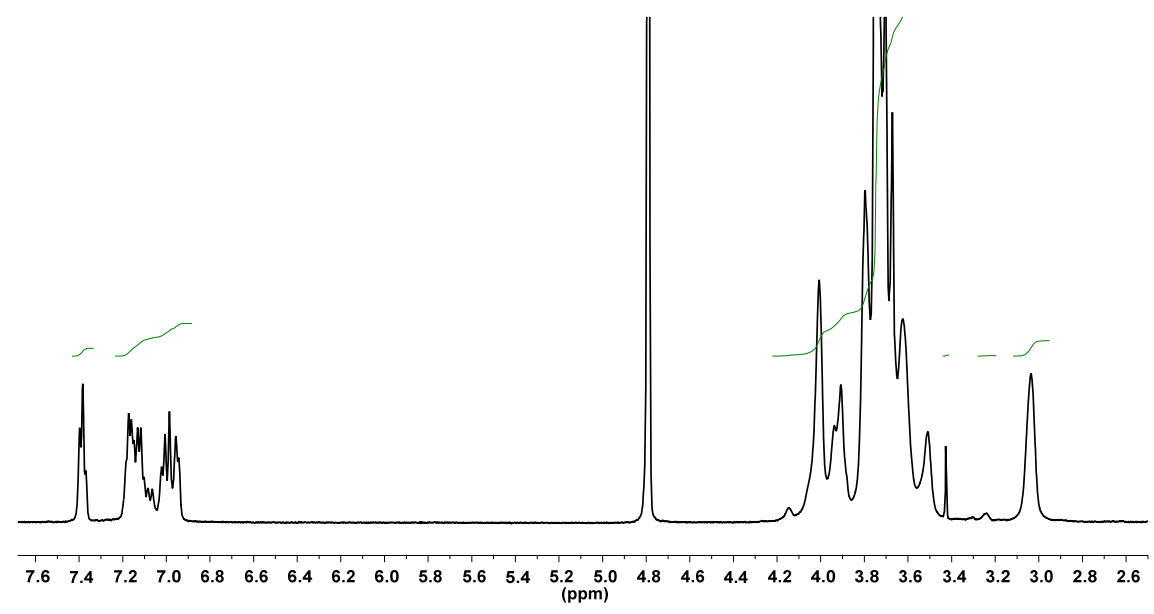

Figure S1. ${ }^{1} \mathrm{H}$ NMR $\left(500 \mathrm{MHz}, \mathrm{D}_{2} \mathrm{O}\right)$ spectrum of PEG-[G3]- $\mathrm{BO}_{2} \mathrm{H}_{2}$.

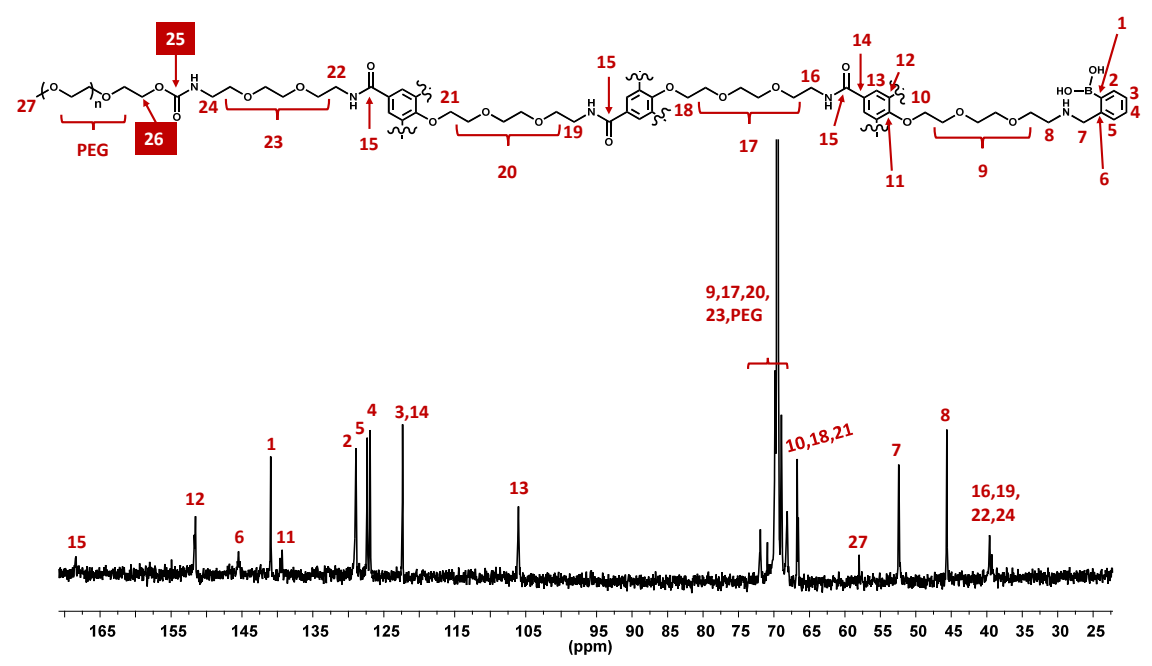

Figure S2. ${ }^{13} \mathrm{C}$ NMR $\left(125 \mathrm{MHz}, \mathrm{D}_{2} \mathrm{O}\right)$ spectrum of PEG-[G3]- $\mathrm{BO}_{2} \mathrm{H}_{2}$. 


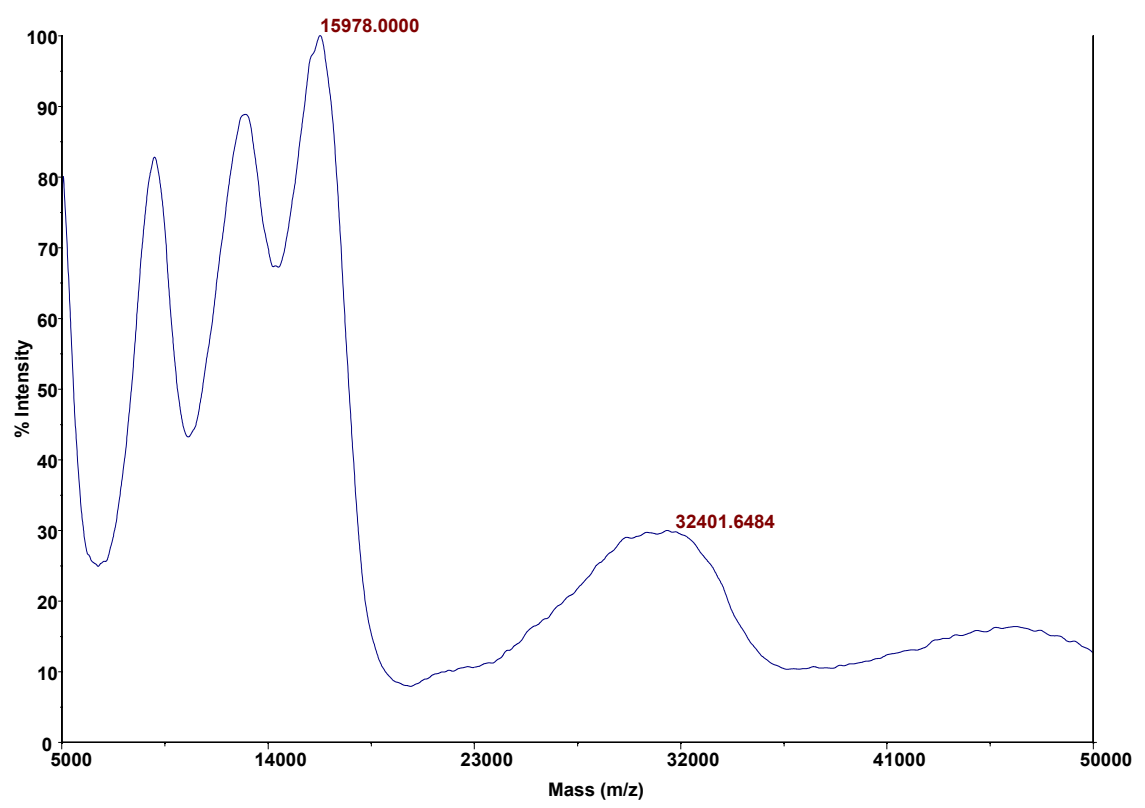

Figure S3. MALDI-TOF MS of PEG-[G3]- $\mathrm{BO}_{2} \mathrm{H}_{2}$.

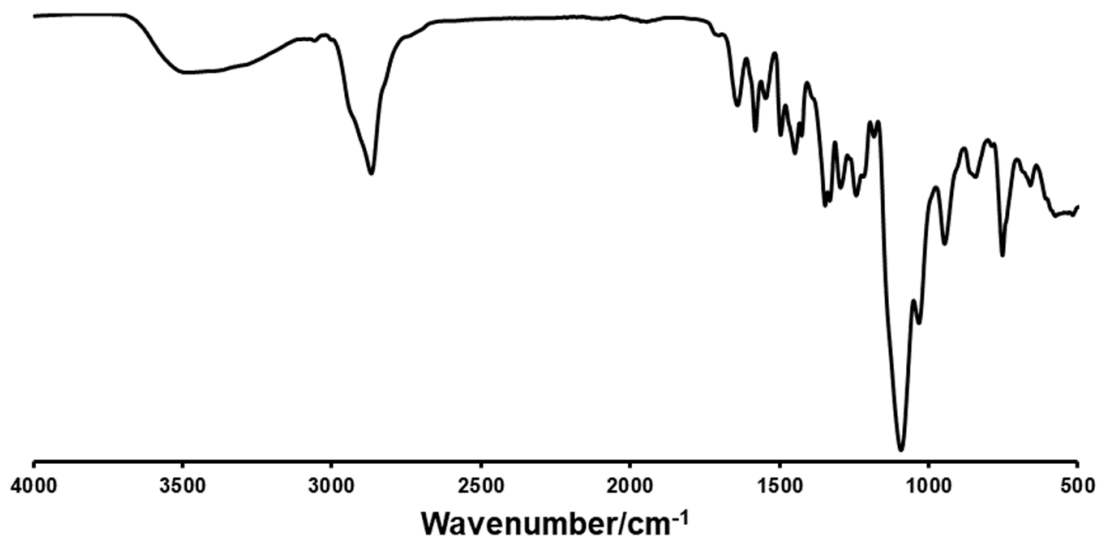

Figure S4. IR spectrum of PEG-[G3]- $\mathrm{BO}_{2} \mathrm{H}_{2}$. 

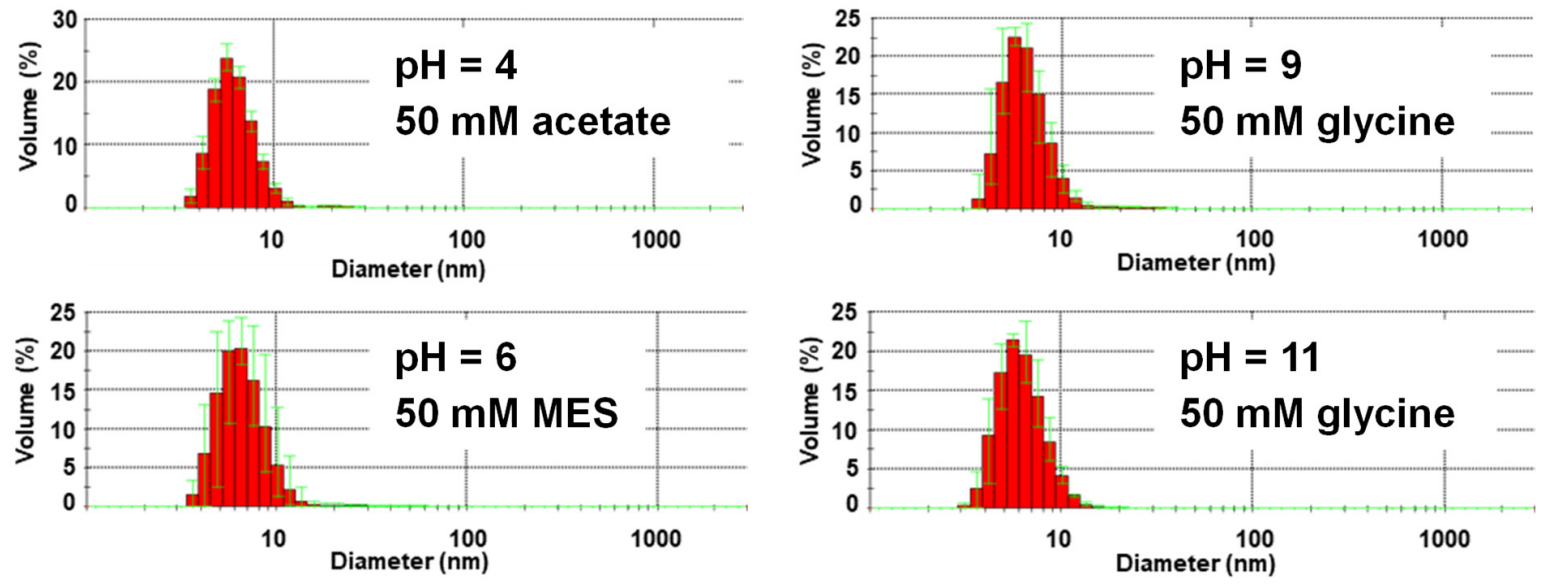

Figure S5. DLS histograms by volume of $\mathrm{PEG}-[\mathrm{G} 3]-\mathrm{BO}_{2} \mathrm{H}_{2}$ at different $\mathrm{pH}\left(15 \mathrm{~h}, 25^{\circ} \mathrm{C}\right)$.

A
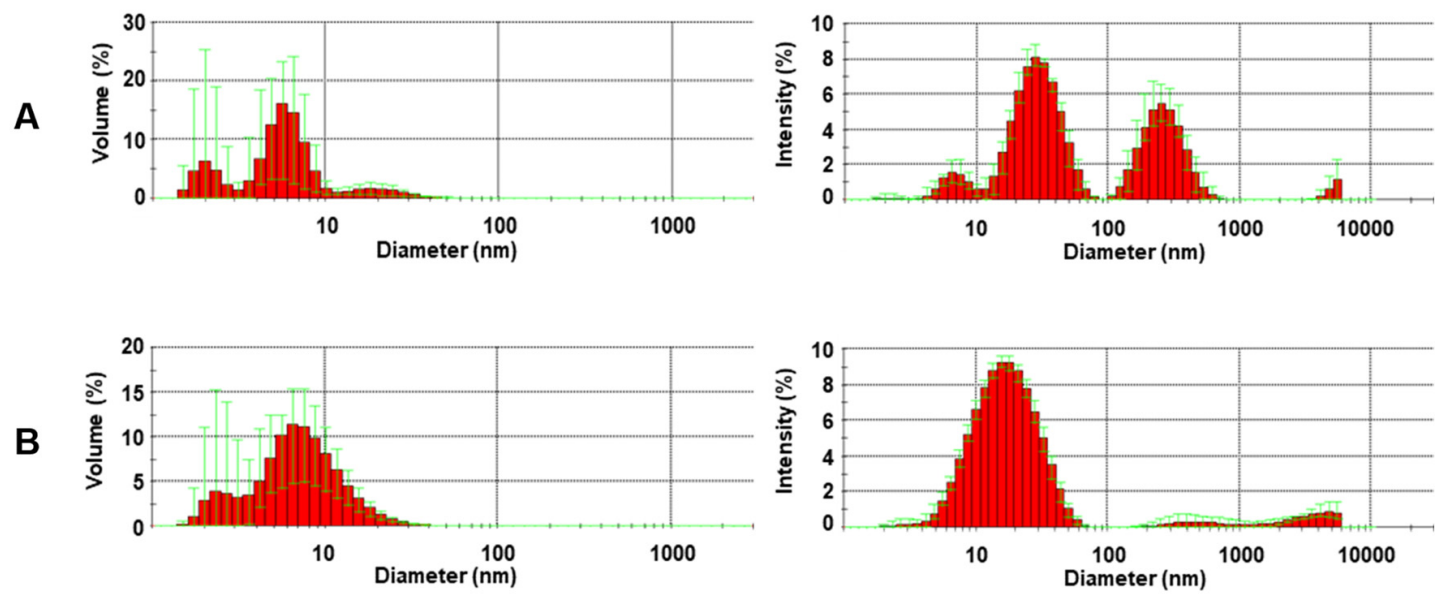

Figure S6. DLS histograms by volume (left) and intensity (right) of GEM ${ }_{85,4}$ (A) and GEM ${ }_{85,8}$ (B) micelles (15 h, $\left.50 \mathrm{mM} \mathrm{PB} \mathrm{pH} 8.2,50{ }^{\circ} \mathrm{C}\right)$. 

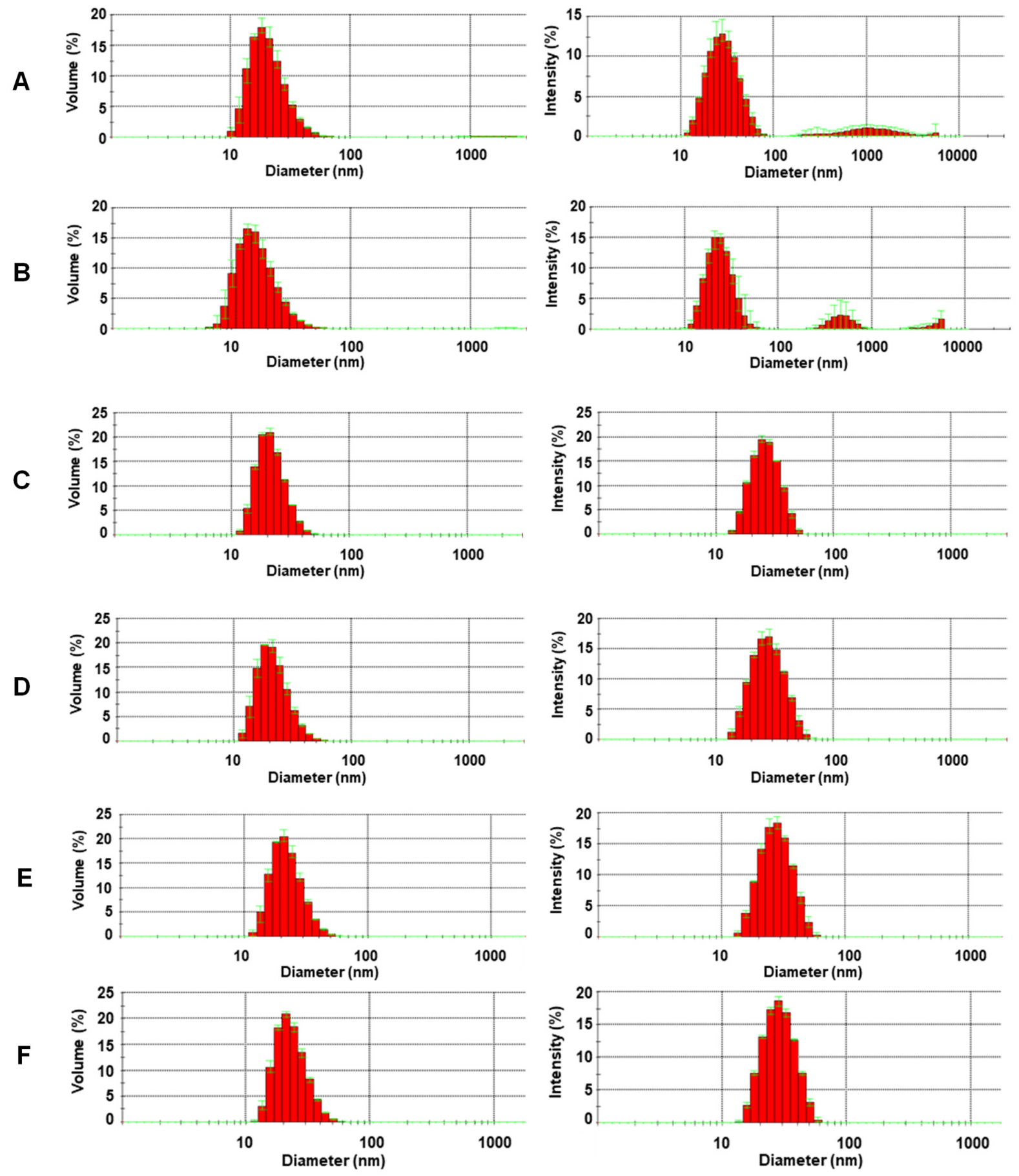

Figure S7. DLS histogram by volume (left) and intensity (right) of $\mathrm{GEM}_{85,12}$ (A), $\mathrm{GEM}_{85,15}$ (C), and $\mathrm{GEM}_{200,15}$ (E) micelles as prepared (15 h, $50 \mathrm{mM}$ PB pH 8.2, $\left.50{ }^{\circ} \mathrm{C}\right)$. DLS of $\mathrm{GEM}_{85,12}$ (B), $\mathrm{GEM}_{85,15}$ (D),

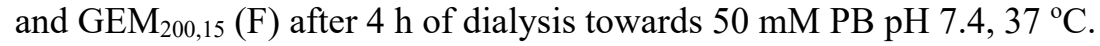


A
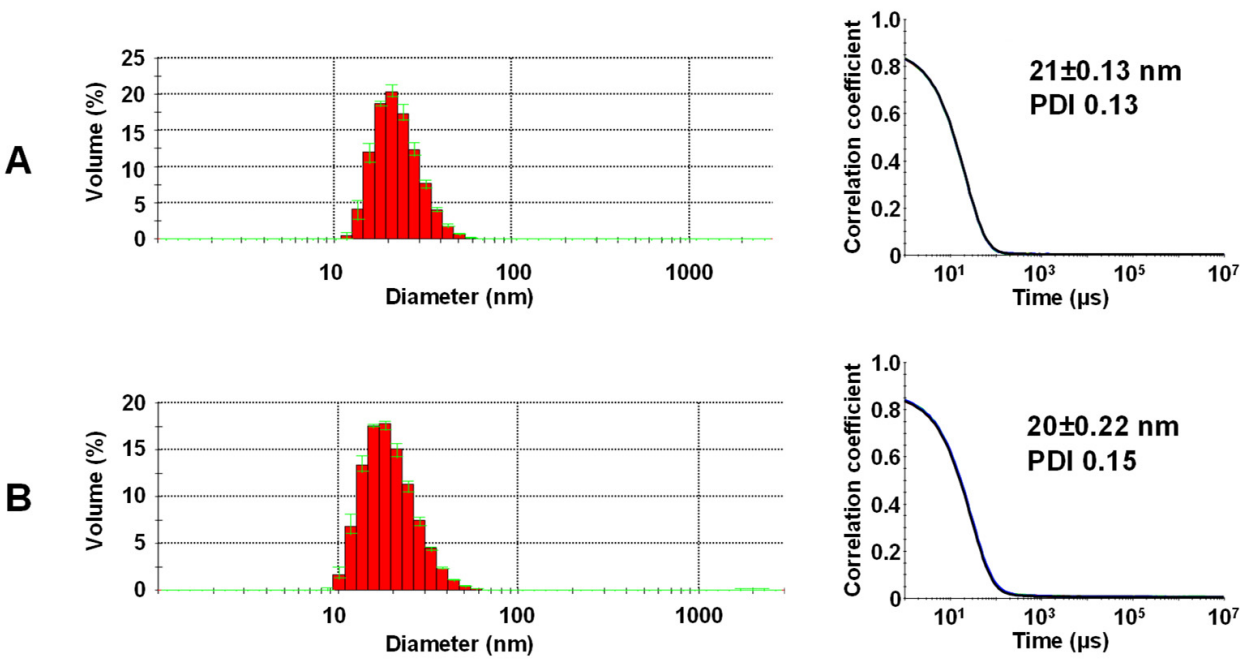

Figure S8. DLS histograms (left) and correlation functions (right) of $\mathrm{CAT}_{15}$ micelles as prepared (15 h,

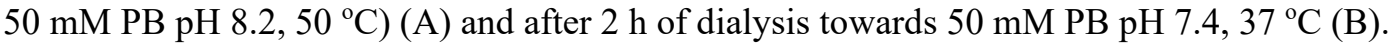
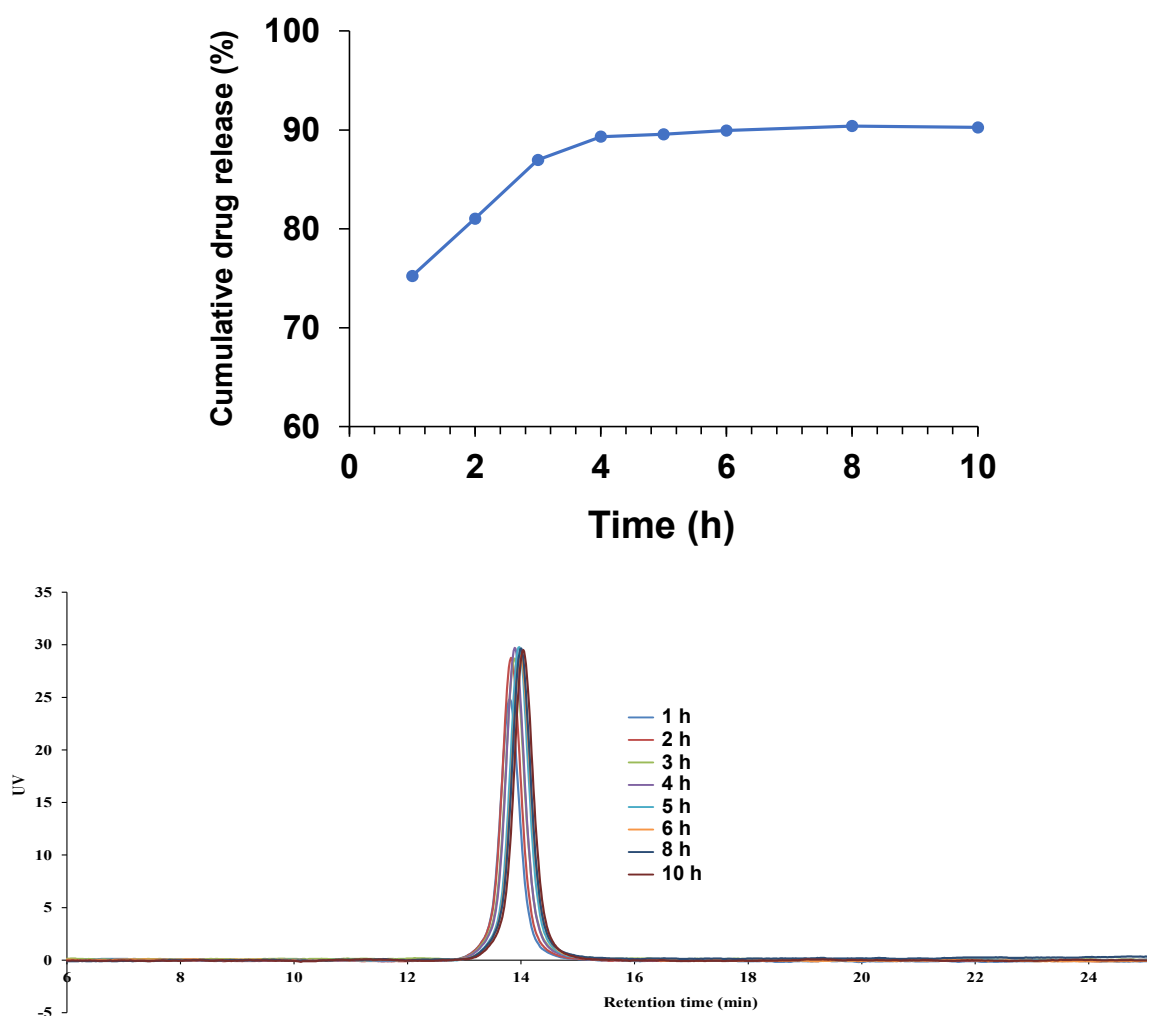

Figure S9. Cumulative GEM release from $\mathrm{GEM}_{200,15}$ micelles determined by dialysis towards $50 \mathrm{mM}$ PB $\mathrm{pH} 7.4,37^{\circ} \mathrm{C}$. RP-HPLC traces $(254 \mathrm{~nm})$ of aliquots taken at different time points. 

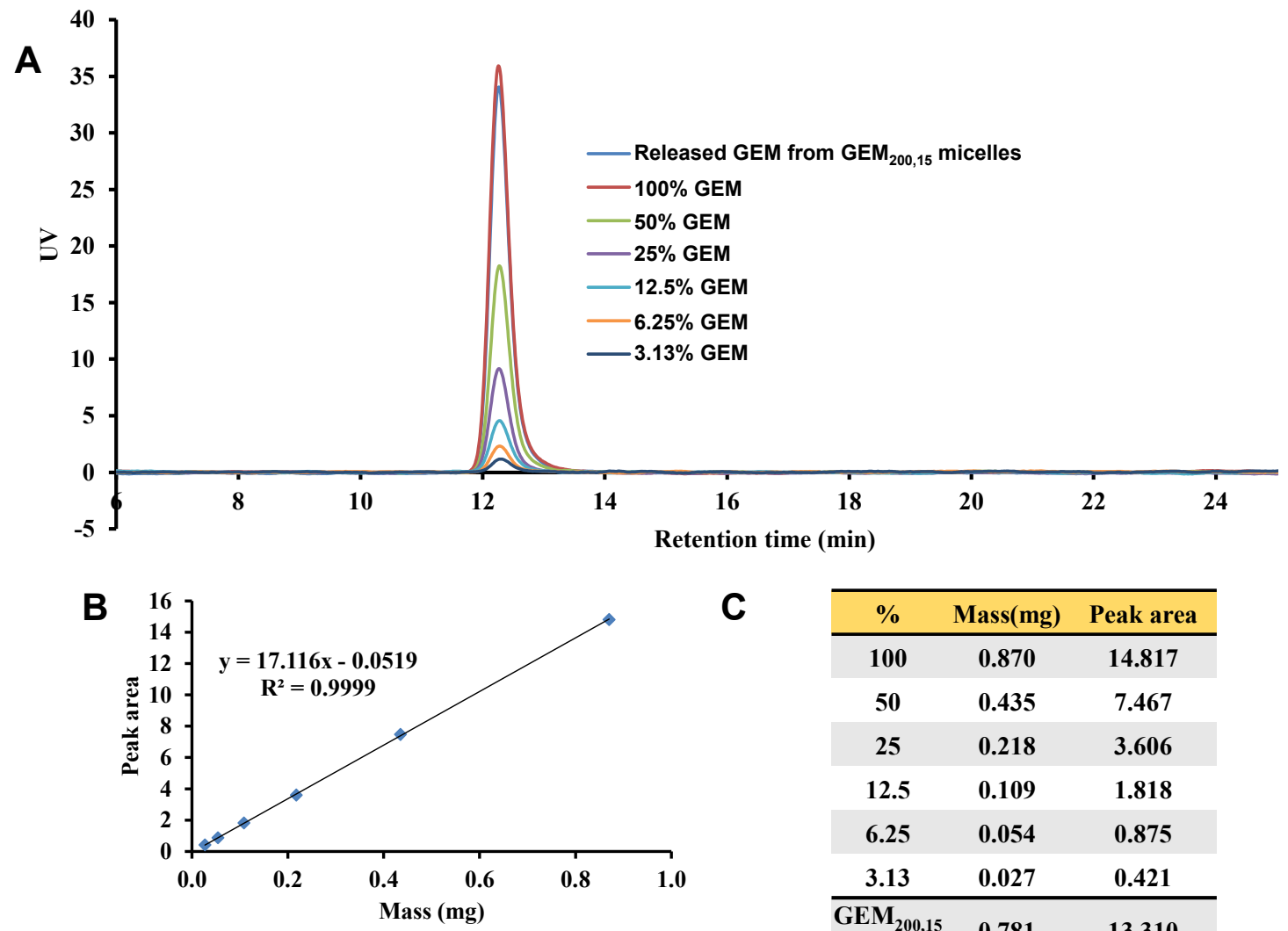

\begin{tabular}{cccc}
\cline { 2 - 4 } C & Mass(mg) & Peak area \\
\hline 100 & 0.870 & 14.817 \\
50 & 0.435 & 7.467 \\
25 & 0.218 & 3.606 \\
12.5 & 0.109 & 1.818 \\
6.25 & 0.054 & 0.875 \\
3.13 & 0.027 & 0.421 \\
\hline $\begin{array}{c}\text { GEM }_{200,15} \\
\text { micelles }\end{array}$ & 0.781 & 13.310 \\
\hline
\end{tabular}

Figure S10. Determination of the EE and DL of GEM in $\mathrm{GEM}_{200,15}$ micelles. RP-HPLC traces $(254 \mathrm{~nm})$ of GEM released by dialysis $\left(4 \mathrm{~h}, 50 \mathrm{mM} \mathrm{PB} \mathrm{pH} 7.4,37^{\circ} \mathrm{C}\right)$ and standards of known concentrations (A). Calibration curve (B) and determination of encapsulated GEM (C).

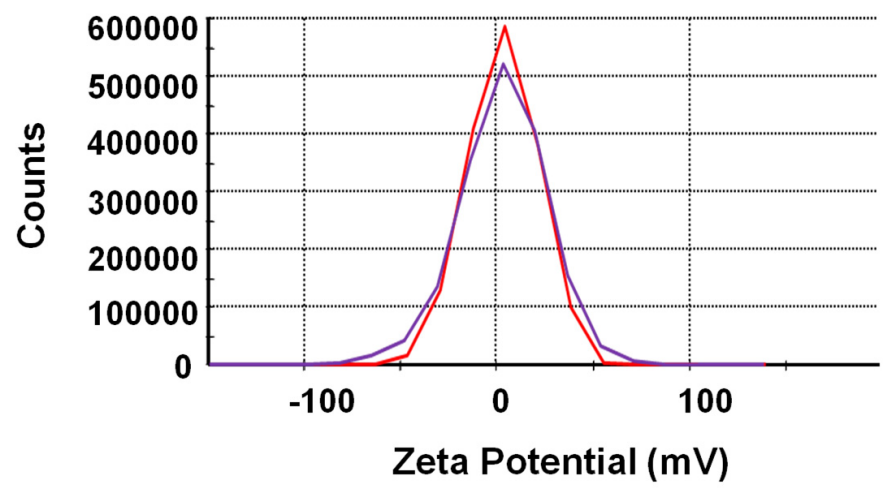

Figure S11. Z-potential of $\mathrm{GEM}_{200,15}$ micelles in $50 \mathrm{mM} \mathrm{PB}$, pH 7.4. 